Zhi-gao Liu, Beijing/ Michael Dunford, Brighton and Beijing

\title{
Rejuvenating old industries in new contexts
}

\author{
The traditional Chinese medicine cluster in Tonghua, China
}

\begin{abstract}
Most research into the formation and development of industrial clusters focuses on hightech clusters or on the upgrading of traditional industries, with little attention to long-term historical perspectives on the revival of old industries in new contexts. Although evolutionary economic geography offers a set of useful concepts for explaining the revival of old industries, it generally concentrates on local factors, neglecting the role of larger scale drivers. To help fill these lacunae, a revised theoretical framework is developed, and used to examine the evolution of the Tonghua traditional Chinese medicine (TCM) industry. Starting from this industry's late-nineteenth century roots, the relationship between the rejuvenation of old industries in particular areas and largerscale systemic changes is examined, paying particular attention to the evolution of this sector during China's transition from a planned to a market economy.
\end{abstract}

Keywords: industrial rejuvenation, industrial cluster, multiple scales, economic transition, evolutionary economic geography, corporate strategies

\section{Introduction}

Since the early 1990 s the global economic competitiveness of local economies has received substantial academic and policy attention (SELlar et al. 2011). Industrial clusters, regional innovation system (ASHEIM/ISAKSEN 2002; COOKE et al. 1997) and innovative milieux (BRAMANTi/MAGGIONI 1997) have been promoted as potentially effective local development strategies by international organizations and governments at various scales in developed and developing countries alike. These concepts have also been deployed in theoretical and empirical research designed to explain the underlying trajectories that lead to success or failure (BOSCHMA/WENTING 2007; HUMPHREY 1995; Martin/SUnLEY 2006; SCHAMP 2005).

A considerable volume of work relates to the formation of high tech clusters (SAXENIAN 1994; STORPER/WALKER 1989; ZHOU 2005) and the upgrading of traditional industry clusters (GIULIANI et al. 2005; HuMPHREY/SCHMITZ 2002; SChAmp 2005). Relatively little special attention has however been paid to long-term historical perspectives on the revival of old in- dustries in new contexts. A major aim of this study is to start to fill this gap by examining the transformations of the Tonghua traditional Chinese medicine (TCM) cluster from the late 19 th century until the present.

In recent years, economic geographers have increasingly considered the transformation of economic landscapes from an evolutionary perspective (BOSCHMA/FrENKEN 2006; BOSCHMa/LAMBooy 1999; Boschma/MarTin 2007, 2010; EsSletZBICHLER/RigBy 2007). Evolutionary economic geography (EEG) draws on evolutionary economics and complexity thinking to understand "the processes by which the economic landscape - the spatial organization of economic production, distribution and consumption - is transformed over time" (BosCHMA/MARTIN 2007, 539).

The emergence and evolution of industrial clusters and other localized forms of industrial specialization is an important focus of empirical EEG research. However, EEG has recently been criticized because of its isolation from other approaches in economic geography, such as the institutional and relational turns (CHUN 2012; MACKINNON et al. 2009; PIKE et al. 2009; 
RAFIQUI 2009). The second challenge the existing EEG is facing is that it generally focuses on local factors (endogenous regional assets and institutions) (CHUN 2012), but explicitly or implicitly neglects the effects of larger scale, regional, national and global factors. This omission is significant as the evolution of industrial clusters is often a result of the collective efforts of trans-local actors operating at multiple geographical scales (COE et al. 2008; YEUNG 2009). A second aim of this paper is therefore to extend the EEG approach to include multiple scales.

EEG originated in Western countries. Extending it to the Chinese case requires considerable modification. First, much greater attention must be paid to the China-specific institutional and cultural context. Second, greater attention must be paid to multiple scales and in particular to some larger scale factors. As global forces have a relatively weak impact on the Chinese TCM, larger-scale factors are largely confined to national ones, and especially to the effects of changing national institutional arrangements. This paper will therefore not just provide an in-depth empirical analysis of the (re)development of an old industry in a context of transition from planned to market economy, but also lead to further theoretical development in EEG, and hopefully contribute to theorizing the economic geographies of Asia and rapidly re-emerging China (YEUNG/LIN 2003).

Tonghua is a small peripheral city in Northeastern China. The Tonghua TCM cluster is one (if not the) most important TCM cluster in China. There are several reasons why we decided to restrict the empirical exploration to this high growth cluster. First, the cluster is a very old one. Its history can be tracked back, at least, to the second half of the 19th century when several family-run TCM businesses already existed. Second, it is an economically competitive cluster in the domestic market. It produces over $40 \%$ of total local manufacturing output. It is also the largest employer in this small city. Third, this cluster went through a profound transformation during the past 150 years. Over time the speed of innovation accelerated, initially through learning manufacturing practices from related industries, in particular from Western medicine, and recently through internal and external (university) research and development (R\&D). Fourth, these developments were highly intertwined with profound changes in business organization and a restructuring of institutional arrangements at international, national and local scales. All of these factors together make the Tonghua TCM cluster a good case to explore, from a longterm historical perspective, the evolutionary trajectory and the successive transformations and restructuring of an extremely old but currently vibrant sector.

The aims of this paper are therefore severalfold. The first is to examine the deep roots of the Tonghua growth cluster's industrial heritage, the trajectory of the rejuvenation of this old industry and its relationships to profound institutional changes occurring at national and local scales. The second is to draw upon, adapt and extend the combined framework of institutional and evolutionary approaches to the study of economic landscapes to afford a better longterm understanding of the revitalization trajectory of a long-established industry.

The paper is divided into five sections. In section 2 we shall integrate institutional, relational and evolutionary economic geographies, and recent literature dealing with industrial clusters, to develop a critical conceptual framework for examining the relationship between cluster evolution and larger-scale systemic changes. Section 3 is devoted to a brief discussion of research methods used in this study. The fourth section turns to consider the development of the TCM cluster in Tonghua. This case study focuses on the key dimensions of Tonghua's industrial context and legacies, governance and policy frameworks, and inter-firm relations. The conclusion draws some wider lessons from the experiences of this industrial cluster through a period of transition from a planned to a market system in China.

\section{Theoretical perspectives and analytical framework}

Economic liberalization and globalization as well as advances in information and communication technology have seen an unprecedented global decentralization of economic activities and a spatial concentration of these industries in a handful of areas. The global fragmentation of production systems may be called a "global shift" (DICKEN 2007), while the spatial concentration of economic activities relates to the de- 
velopment of industry clusters. To increase income, create job opportunities and sustain regional competitiveness, policymakers have made great efforts to cultivate and upgrade these "dense concentration[s] of interdependent small- and medium-sized enterprises (SME) in a single sector and in auxiliary industries and services" (DUNFORD 2006, 27).

However, one region cannot easily replicate the success of another. As a result recent industrial cluster literature has focused less on the empirical assessment of the occurrence and importance of agglomerations and more on a quest for a deeper understanding of underlying conditions and development trajectories (HUMPHREY 1995). However, existing work concentrates either on the development of new, cutting-edge technologies or on the upgrading of labour-intensive industries. Although cluster scholars have already recognized that already established clusters have roots either in the presence of related industries (BoschMA/WENTING 2007) or supportive institutions (SCOTT 2002), they largely overlook the rejuvenation of old technologies in a small number of old industrial areas (LIU 2009; HASSINK 2007). To explain the development of clusters, EEG offers an adequate analytical starting point, since it employs generalised Darwinian, path dependence and complexity theories to "explain ... the spatial evolution of firms, industries, networks, cities and regions from elementary processes of the entry, growth, exit and relocation of firms" (FrENKEN/Boschma 2007, 635).

Conventional Western evolutionary approaches themselves have, however, certain limitations. First, they have concentrated on endogenous local factors, such as the emergence and diffusion of new technologies in a local industrial community, paying insufficient attention to the effects of higher-level factors. Second, EEG has drawn insufficiently on ideas from the equally useful contemporary economic geographies, particularly institutional and relational approaches (RAFIQUI 2009). Indeed, the evolution of industrial clusters can only be well understood if institutions at various geographical scales and underlying social relations are fully taken into account (AMIN 2001; MARTIN 2000). This argument applies all the more strongly if the Western EEG approach is to be applied to transitional economies such as China where there are distinctive institutional and socioeconomic conditions and distinct types of economic actors. Third, insufficient attention is paid to theories of the firm and the ways in which the conduct of firms is shaped and in turn shapes their environment. In this paper therefore the conventional EEG framework is modified in two ways to permit an analysis and explanation of the long term evolution of rejuvenated old industries in the context of economic transition in China. First, we shall adopt a firm- and sector-centred approach to the study of the Tonghua TCM. Second, we shall adopt a multiple scale perspective.

At the root of the choice of a firm- and sectorcentered approach is the view that at the centre of changes in size, structure, and trajectories of enterprises and the geography of industries are enterprise strategies and their context (Fig. 1). In shaping industrial change enterprises are the most important actors and their strategies and the internal and external factors that shape them are the main drivers of industrial change. However, enterprises operate in particular geographical, social and institutional contexts. These contexts or environments are multiscalar varying from the global level through the national to the local, and their effects are felt not just in the local milieu, but in the value chain and the network of relationships in which an enterprise is embedded. In the case of the Tonghua TCM this environment is characterized by elements of continuity and elements of change. In China a there is a 2,500 year Confucian tradition in which the common good counts for more than individual aspiration, a tradition of a commodity-producing (market) economy developed and regulated by a hierarchically organized central state, and collective ownership of economic assets, the existence of a strong state and of rule by public officials (guan ben wei), and the significance of guanxi (personal relations).

Aspects of this environment have changed quite radically on several occasions. In 1949 the establishment of the People's Republic of China led to the introduction of a centrally planned economy. After 1978 the adoption of a programme of reform and opening up saw movement in the direction of market socialism with Chinese characteristics. These two transitions have led to fundamental changes in the economic and social fabric of the country, including resource allocation principles, ownership and property rights, labour relations, wage 
distribution, central-local relationships and the social welfare system (QIAN 2000). The shift from a centrally planned to a market-oriented economy initially allowed individual enterprises to make pricing, production, and distribution decisions, granted autonomy to enterprises and local states, subsequently diversified the enterprise ownership system, and ultimately expanded the scope of the private sector through the restructuring and privatization of stateowned enterprises (SOE) and the creation of private startups (GuO 2003). The transformation of the ownership of firms is essentially a process of organizational innovation, which in turn increases the likelihood of technological innovation. Alongside this nation-wide institutional and social context, the wider environment also provides a series of more specific resources, assets and opportunities including relations with suppliers and customers, centres of education and research, sources of capital and government support.
As far as enterprises themselves are concerned, their strategies depend first and foremost on the nature of the prevailing social order. In an administered or planned economy the main aim of enterprises was to acquire and mobilize resources to meet output targets: The fundamental uncertainties relate not to the sale of outputs but to shortages of material and human resources. In a market system the aim is to earn sufficient revenues to recover the costs incurred and secure a surplus to finance future growth and development. The fundamental uncertainties relate to the sale of outputs.

These strategies of enterprises result in the coexistence of mechanisms of differentiation and equalization of conditions of production and exchange: Enterprises seek to innovate to improve their position relative to their rivals generating new differences and seek to catch-up by copying or learning from the experience of others. More specifically, enterprise strategies in a market system involve a combination of (1)

Fig. 1: Conceptualising the evolution of clusters

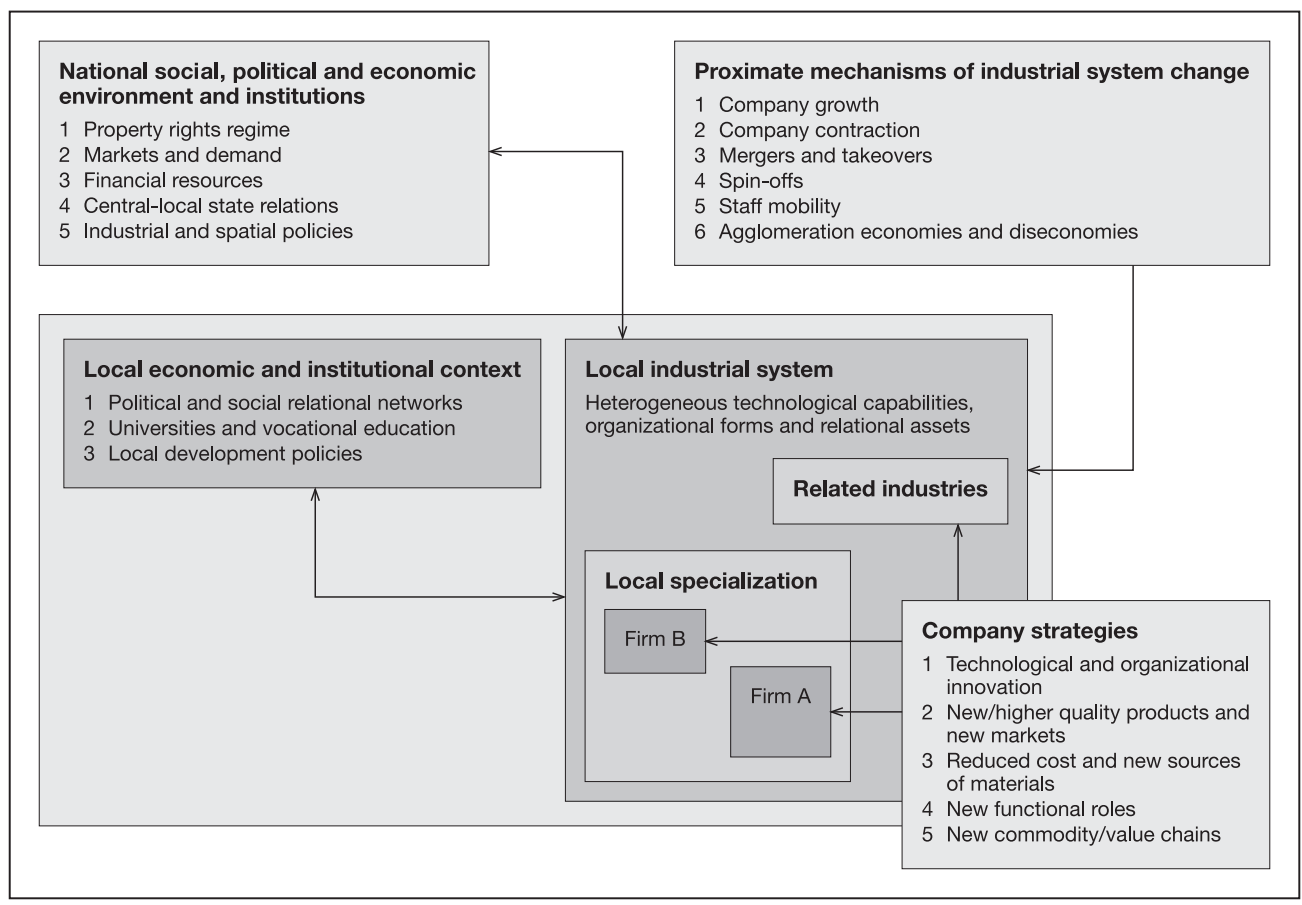

Source: own draft 
cost-reduction strategies, (2) the development of new or improved commercially relevant products, or entry into new markets, (3) changes in the relative weight of different functional roles, and (4) disinvestment and movement into other value chains (DUNFORD/GRECO 2005). Enterprise strategies can also involve attempts to expand through the takeover of other enterprises and their assets and resources, or the spin-off of new companies from existing enterprises or related activities (Fig. 1). In addition enterprises may seek to attract talented people or skilled employees from rivals, partners or unrelated activities in order to enable them to achieve their goals. All of these changes alter the structure of the local system, the wider value chain and the wider economic order. These changes result in a transition to a new structure. Fig. 1 is a cross-sectional representation of a system subject to constant diachronic change; in this paper a sequence of cross-sections corresponds to the phases of a periodization developed from the working of the causal mechanisms identified in the figure. The choices made and the impacts of these actions depend on their context and on the resources, structure and functions of enterprises. Of these goals in the TCM sector, product development is of particular importance.

The adoption of this starting point, involving as it does a quest for satisfactory returns and a quest to keep abreast of the demands of customers, may also be construed as attempts to upgrade. Construing it in this way enables a connection to be established with the value chain literature. This literature is itself a development of the literature on commodity chains and input-output structures, and has the advantage of examining 'what' questions concerning the strategies of firms as well as 'where' and 'when' questions. Close relationships also exist with other traditions including Schumpeter's concept of innovation which included: (1) the introduction of a good or a new quality of a known good; (2) the introduction of a method of production or a mode of commercial management new to the sector; (3) the opening up of a new market whether or not it previously existed; (4) the conquest of a new source of raw materials or semi-manufactured goods; and (5) the establishment of a new organizational model in any industry, including the creation or dismantling of a monopoly position (SCHUMPETER 1934). All of these considerations are central to a theory of the firm and a theory of industrial systems and represent important ways of further developing EEG approaches.

As emphasized in EEG research, the enterprises of which an industry or a cluster is made up are heterogeneous. Heterogeneity is a feature of all economic systems yet changes over time as a result of the coexistence of mechanisms that increase (differentiation) and decrease (equalization) inter-firm differences. The heterogeneity of individual units influences not only their ability to compete and survive (competition and selection) but also to adapt themselves to their changing environments (variation) (EssletZBICHLER/RigBY 2007). Mechanisms that produce variation increase heterogeneity (variety and diversity), maintaining volatility, while competition and selection mechanisms reduce diversity, enhancing stability. Micro-heterogeneity (novelty), and the maintenance of a reasonable degree of diversity, are both of importance to long-run systemic evolution (ESSLETZBICHLER/RIGBY 2005; METCALFE 1998). However, heterogeneity itself in a planned economy means something totally different from that in the competitive environment of a market economy. Since enterprises in the planned economy period were assigned to an administrative level similar to a government department, their differences involved and were closely related to their positions in the administrative hierarchy (CHIU/LEwIS 2006, 60; Hu 2005). The different administrative levels with which an enterprise was affiliated, partially determined differences in technological capability, organizational forms, and the relation with customers. However, the transition to a market-oriented economy has enabled enterprises to break free from the traditional administrative hierarchy, and their heterogeneity is embodied more in organizational and technological capability, although the relation with state remains of great importance.

This process of creating novelty is the process of innovation. Innovation has technological product and process aspects and non-technological organizational aspects. All aspects of innovation are of importance in creating innovative entities and competitive regions (ARMBRUSTER et al. 2008; CHANDLER 1962; NELSON 1991). In existing empirical EEG studies of industrial clusters, the importance of technological innovation has been widely recognized. The role of other aspects of innovation, and, in 
particular, of organizational innovation has received much less attention. Actually, organizational innovation is a particularly important aspect of industrial development in China's transition periods. Technological innovation is often economically risky owing to the absence of intellectual property laws (prior to 1984) and the weak protection of intellectual property rights. In the period of commodity shortages, enterprises could make profits through production-capacity expansion and quality improvement without significant technological improvement. Abandoning existing low-added value functions and developing new and higher value added activities (functional upgrading), is a particularly important aspect of industrial development in developing countries (HUMPHREY/SCHMITZ 2002). In the case of TCM firms developing marketing, advertising and branding capabilities are good ways of increasing economic returns.

China's successive transition periods to a planned economy and from a planned economy to a socialist market system were moreover periods of economic and institutional novelty in the sense they saw significant organizational and institutional change in the shape of new firms, new organizations and new institutions emerging in changing macro-scale socioeconomic settings. Although the (re)emergence of industrial clusters was a result of the joint effects of trans-local actors operating at national, regional and local scales, in industries subject to strict state regulation such as the TCM, the changing national-level economic and institutional conditions were of particular significance. Global factors and multinational corporations had very limited effects. In transitional periods, changes in the macro-scale economic and institutional environments provided new opportunities to create new organizational forms and to introduce new technologies. For example, the gradual relaxation of constraints on property ownership after China's reform and opening-up enabled organizational experimentation, leading to a slow dissolution of the formerly hegemonic form of state-owned enterprises (SOE) and an increasing diversity of organizational forms. New types of ownership and new firms not only partially broke up the old production system and reshaped the technological system, but led also to competition among firms and organizational forms. Moreover, increasing market demand stimulated many firms to expand rapidly, introducing com- petition into economic life, the selection of certain innovations and certain novelties and a winner-takes-all situation in relation to technology and organizational forms. The change in the macro-environments during the transition period seemingly offered all regions an equal opportunity. However only a small number of regions were successful in seizing these opportunities and achieving economic prosperity. Why can an industry in one area be re-juvenated while others cannot?

This issue is related to a long-lasting but ongoing debate about the relationship between specialization (the Marshall-Arrow-Romer externalities) and agglomeration economies ( $\mathrm{Ja}$ cobs' externalities). Recently, EEG scholars have moved beyond black-and-white categories and suggested that new industries are more likely to emerge from (technologically) related industries (Fig. 1), through spin-off activity, firm diversification, labour mobility, social networking and other mechanisms (FRENKEN et al. 2007) or through a local supply of potential entrepreneurs, knowledge externalities, and skilled labour (BoschmA/WENTING 2007). Similarly, an old industry may have a higher probability of rejuvenation in regions where related activities are abundant. For example, the adoption of separation analysis, identification and processing technologies and similar innovations used in developing chemical drugs are useful for modernizing a declining TCM industry, and can indeed bring about revolutionary changes in this old industry. The creation of spin-off firms not only increases the number of firms in a given industrial cluster, leading to increasingly fierce competition, but also diffuses innovation and knowledge, because spin-offs inherit the technological and managerial capabilities of parent firms. Once moreover a niche market is opened up, established enterprises in related industries can diversify, and enterprises in other areas can swarm into the emerging cluster (agglomeration economy). Labour mobility is another important mechanism for proliferating knowledge within a cluster as a firm's knowledge and skill is embodied in the entrepreneur and in specialized workers. Social networks also play a pivotal role in mobilizing resources at below-market prices, lobbying for government support and shaping new preferential development policies. State support can in turn make a significant contribution to the emergence and development of revitalized industry clusters. In 
the context of economic transition, finally, the role of the transformation or ownership arrangements cannot be ignored (JIANG/MURMANN 2011). As said before, transformation of the ownership of firms is organizational innovation that breaks free of the older mechanisms of organizing resources and possibly increases the likelihood of adopting new technologies (GRABHER/STARK 1997). However, transforming this possibility into actual outcomes depends on the availability of financial resources, whose function is underplayed in EEG.

In short, the evolution of industrial clusters is a key issue in economic geography. EEG offers a way of exploring how heterogeneities (new firms, new industrial structures and new industries) come into existence, survive and diffuse in time and space. The evolution of economic landscapes involves processes of knowledge heredity, variation, selection and competition (METCALFE 1998; NELSON 1995).

These proximate causes are not only determined by individual firms, but are also conditioned by the external institutional and economic contexts (Fig. 1). However, Western EEG has concentrated too much on the role of local factors, ignoring larger-scale factors shaping the (re)development of industrial clusters, and requires adaptation in the Chinese case to reflect the role of specific local and national institutional conditions and actor characteristics. In the case of China's transition from plan to market, the changing macro-scale socio-economic setting offered new opportunities for local firms to break free from old production and technological structures and relational configurations. Its influence on regional development however was not even spatially. The reason why was that the local socio-cultural embeddedness of economic activities and established economic and relational structures led to a certain degree of lock-in of regional development to existing trajectories, while at the same time influencing concrete ways of reshaping development paths in those places that broke free. Organizational and ownership restructuring, spin-off dynamics, agglomeration economies, labour mobility and place-specific social networks created and replicated new routines and heterogeneities within industrial systems, and made possible the rejuvenation of industrial clusters in China. This ability to produce and diffuse novel technologies and organizational forms and pro- mote long-term development depends however not just on capabilities within a local industry but also on the appearance of a range of technologically related industries in a region, as we shall show in relation to the Tonghua TCM cluster.

\section{Research methods and data sources}

This paper draws on research material collected mainly in fieldwork conducted in June and July 2007 and subsequent internet and telephone-based data gathering. Historical data was collected from two government agencies, the Tonghua Pharmaceutical Industry Administrative Office and the Tonghua Science and Technology Bureau. Historical documents included industrial reports, activities reports, periodicals and publications, public speeches, enterprise chronologies, the biographies of major figures, statistical series and previous studies (such as WANG 2006; Hou 2007).

35 semi-structured interviews were conducted with local business managers or owners. The size of the firms varied from large companies with more than three thousands employees to small and medium-sized companies with about a dozen people. In the case of large companies, vice-presidents or higher level managers were interviewed, while most of the people interviewed in the medium-sized enterprises were business owners. These firms were introduced by local officials working for the two above mentioned government agencies, drawing on their own personal contacts. The interviews were used to investigate the history of the firm, technological development and key technology sources, interactions with other firms, and relations with government agencies and research institutes. In order to understand better the evolutionary and (re)development process of this long-established industry, the in-depth interviews covered issues such as 1) the changing profiles of the interviewed firms including their establishment, investment and employment structure, major products and market allocation, 2) the changing ownership structure, product development and investment strategies, 3) and changing organizational forms and social networks.

A further eleven in-depth interviews were conducted with government officials and policymakers from the Development and Reform 
Commission, the Science and Technology Department, the Food and Drug Administration in Jilin Provincial Government/Administrative Office of the Pharmaceutical Industry, and the Department of Science and Technology in Tonghua Municipal Government and district/county offices. The major objective of the interviews with officials was to understand the development trajectory of the TCM industry and changing demand and market conditions; the impact of changing policies at various levels of government on the TCM industry and on Tonghua as well as the changing local industry strategies especially for developing TCM in Tonghua. In-depth interviews were conducted also with scholars, public policy researchers and industrial experts from Jilin University, Northeast Normal University, Jilin Academy of Social Sciences in Changchun, Tonghua Normal University in Tonghua and with industry association representatives on the provincial and local levels to collect opinions and comments on policy support for the industry and its effects. In general, each of the interviews lasted around one hour. Most interviews were recorded and transcribed in Chinese and key sections were translated into English. The combined methodology of qualitative interviewing and study of historical documents enabled the facts of the industry's evolution to be established and permitted identification and interpretation of successive innovation practices.

\section{Structure and evolution of the Tonghua TCM cluster}

\section{Profile of Tonghua TCM cluster}

TCM has a rich history and is widely practiced in East Asia (Lu et al. 2004) where it is considered an alternative and complementary to Western medicine (EISENBERG et al. 1998). Although it is not the dominant form of treatment, TCM still plays a significant role in treating diseases, especially chronic diseases, in contemporary China. After China's economic opening up and reform the geography of Chinese TCM manufacturing changed considerably. New economic, legal and political institutions, market growth, and the execution of good manufacture practice (GMP) policy saw increased spatial concentration of the highly fragmented TCM production system and the emergence of some domestically competitive TCM industry clusters. Amongst them, the Tonghua TCM industry is outstanding.
Tonghua city is a prefecture-level administrative area and is at the second level of China's contemporary administrative hierarchy, below the provincial but above the county level (see MA 2005). Tonghua city is located in Changbai Mountain on the China-North Korea border, and comprises two urban county-level districts (Dongchang and Erdaojiang district) and five surrounding counties (Huinan, Liuhe and Tonghua, Meihekou and Ji'an county), with an area of around 15,200 $\mathrm{km}^{2}$ and 2.3 mio. inhabitants. Historically Tonghua was an agricultural area with a long history of planting medicinal herbs and making traditional medicines, like other mountain areas in China. Although the origin of Tonghua's TCM industry can be traced back at least to the second half of the $19^{\text {th }}$ century when there were several small family-run TCM businesses, the acceleration of its industrial development was a result of rapid rural industrialization in the mid-1950s. From the very beginning until the end of the 1970 s, Tonghua did not differ greatly from other rural areas in China with a long history of TCM manufacture, where, alongside TCM, the manufacture of chemical pharmaceuticals was also encouraged primarily to meet the needs of local residents. Township-owned enterprises (TOE) predominated in both of these sectors and had close relationships with the local state. Although their economic performance was not strong, development at that time provided a platform for the later development of the pharmaceutical industry in Tonghua, training a large number of skilled employees and managers. Driven by the first wave of economic growth after the adoption of the opening up and reform programme, the Tonghua pharmaceutical industry entered a rapid development stage. Existing and newly established plants all started to transform the large-scale manufacturing of ginseng-based Chinese medicine. Notwithstanding the decline in the number of firms owing to mergers and acquisitions, the mid-1990s saw the TCM industry in Tonghua emerge as the second largest local manufacturing sector, both in terms of output value and employment. In 2010, there were 94 pharmaceutical manufacturing plants (82 GMP-certified), employing 17,000 people and producing more than $30 \%$ of total output value in this area.

The Tonghua TCM industry developed from a couple of small-sized and relatively inefficient enterprises to become a competitive cluster in 
Fig. 2: The actors of Tonghua's pharmaceutical industry

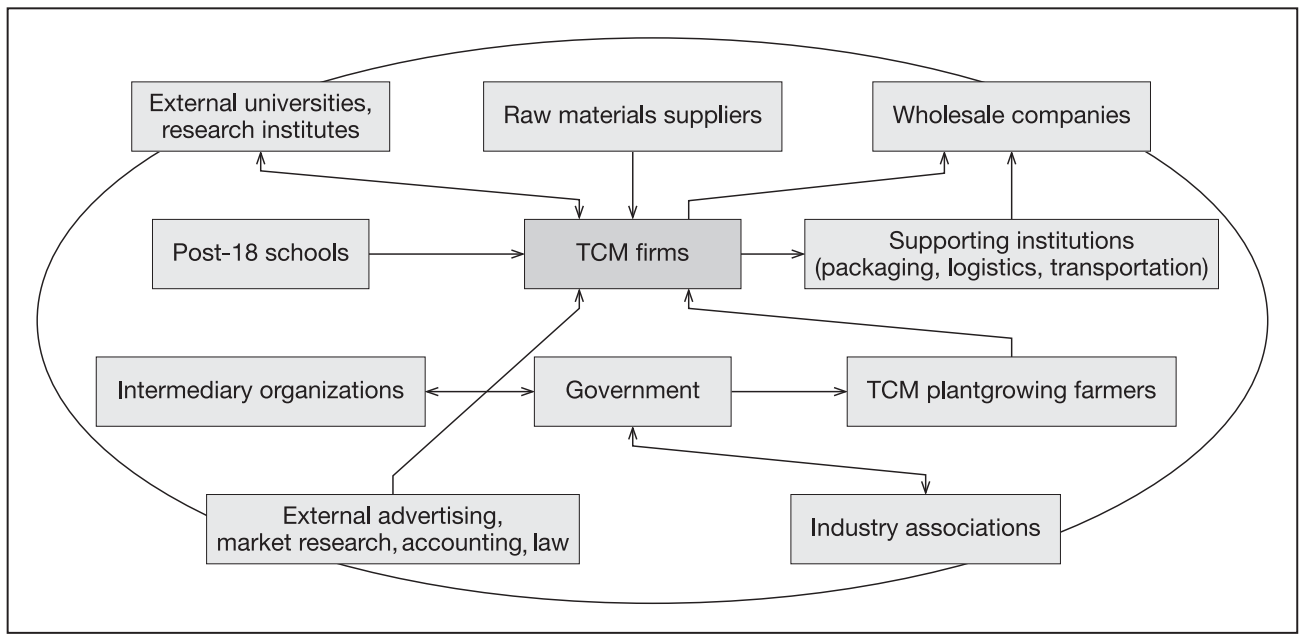

Source: own draft

China, with some of the characteristics of Italian industrial districts (MARKUSEN 1996), albeit with a low degree of innovation. Although some enterprises, including the Xiuezheng Group and the Dongbao Group, have already joined the list of China's top 50 TCM enterprises by sales, the majority of the pharmaceutical manufacturing plants are small- and medium-sized. As the TCM manufacturing sector grows, supporting or related sectors developed synchronously in this area. At present there are around 40 pharmaceutical wholesale companies, over 200 clinics and pharmacies, at least 30 logistics companies, and approximately 80 packaging companies (Fig. 2).

Tonghua is not a metropolitan area, and has just two post-18 schools (a college and a vocational training school), training low- and middle-level skilled workers, rather than pharmaceutical scientists. The Tonghua TCM firms are mainly engaged in production activities, but developed extra-cluster-linkages to compensate for local supply shortages of technology and knowledge. The neighbouring metropolitan regions, where many high-ranking pharmaceutical universities are located, such as Changchun and Shenyang, provide higherquality resources, such as well educated engineering personnel and scientists, and knowledge-intensive service activities, including new drug development, management consult- ing, and market research. A considerable portion of the highly educated personnel are recruited from these metropolitan regions. Furthermore, large TCM enterprises created R\&D collaboration networks with pharmaceutical universities and research institutions, in the above mentioned regions, while a few, such as the Xiuzheng Group and the Dongbao Group, both established research centres both in Changchun and Beijing.

\section{Evolution of the Tonghua TCM cluster}

To examine the relationship between the (re)development of the Tonghua TCM industry and larger-scale systemic changes, the development process of the pharmaceutical industry in Tonghua is divided into different periods. These periods derive from the combination of several factors: declines and increases in the number of firms; distinct entry strategies and changing national and local institutional arrangements. Altogether four stages of cluster development can be identified: the period prior to $1984,1985-1991,1992-1997$ and the period from 1998 onwards. Considering that in the first years of China's reform and opening-up programme, impacts on the Tonghua pharmaceutical industry were limited, and that it was in 1984 that Tonghua city assumed its current administrative shape, the first period is considered to extend from 1949 (the establishment of the new China and of a planned economic sys- 
Fig. 3: Geography of the Tonghua TCM sector (GMP-certified firms)

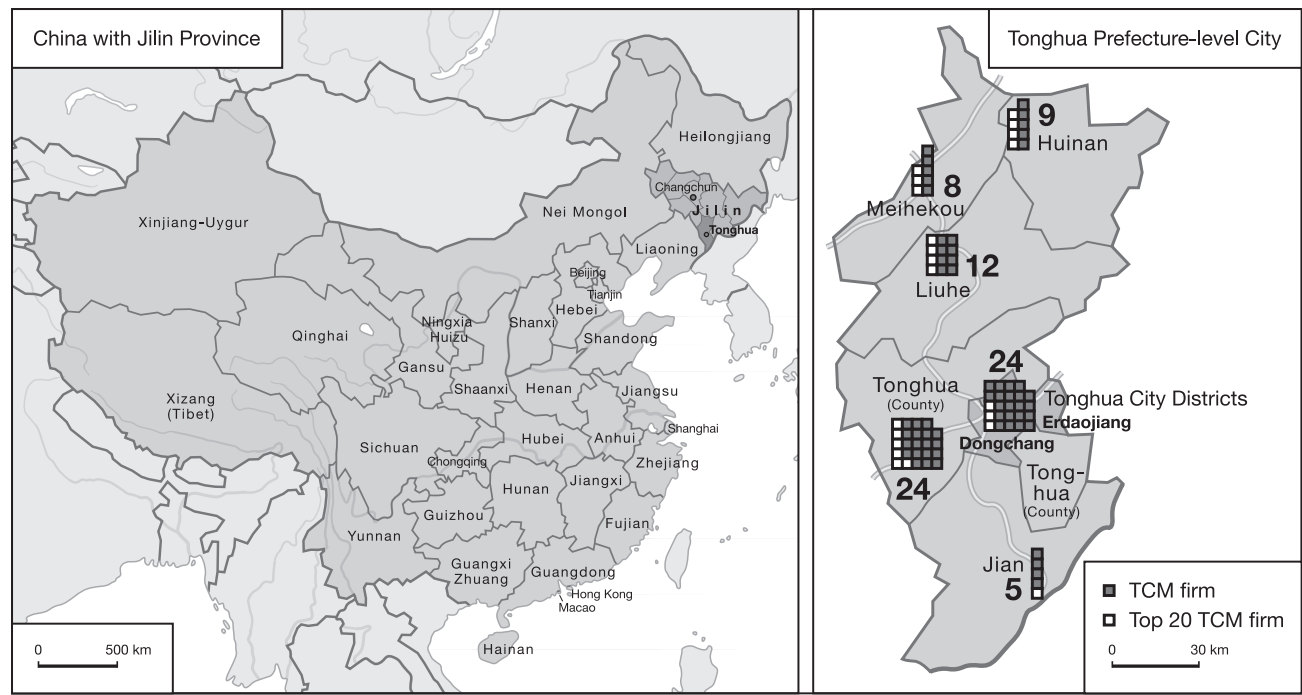

Source: The Tonghua City Administrative Office of Pharmaceutical Industry; cartography: Jialing Zou

tem) to 1984 , although some attention is also paid to the period from 1875 (the first year for which data are available) as a number of the firms operating in the planned economy period date from the late nineteenth century. The very limited number of pharmaceutical firms in the planned economy laid the foundations for subsequent industrial development.

During the second period from 1985 to 1991 the number of pharmaceutical firms increased slowly. Almost all of the new enterprises were established by local government agencies, but were partially privatized. After 1992, a large number of private enterprises developed, and the large-scale state-owned/collective pharmaceutical firms in Tonghua began to be privatized. Mergers and acquisitions (M\&A) and corporate restructuring were frequent, and the overall number of firms increased (Fig. 4).

Prior to 1984 - nineteenth century emergence and the planned economy phases: In the years from 1875 to 1984 , Tonghua's pharmaceutical plants underwent two significant socio-political and economic transformations, first from proto-capitalist enterprises in a predominantly pre-capitalist society to centrally planned socialism after 1949, and second from a planned to a socialist market economy with Chinese characteristics starting in 1978. In the planned economy, the Tonghua industry was characterized by SOE and TOE with direct and intensive local government intervention. These enterprises were relatively small in size compared to the metropolitan industry complexes in which large-sized state-owned pharmaceutical enterprises were located.

In the late 1880 s, several family-owned TCM businesses already produced for local farmers.

Fig. 4: TCM firm number from 1958-2010

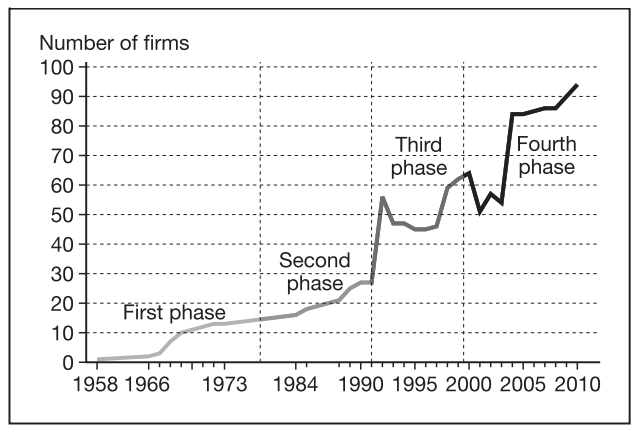

Source: The Tonghua City Administrative Office of the Pharmaceutical Industry 
In 1958, shortly after the Chinese Communist Party came into power in China, these TCM workshops were restructured to establish the first modern pharmaceutical enterprise (Tonghua City Pharmaceutical Factory). In about 2000 this enterprise was acquired by the Xiuzheng Group that is currently a national champion in the TCM industry but grew from a small, local mill. Encouraged by a rural industrialization strategy, Tonghua's first generation of new pharmaceutical plants was established to produce necessary medicines for local people. In 1967 there were just three plants. By 1972 this number had reached 13. A majority of the enterprises were specialized in producing chemical pharmaceuticals, partly because Western medicine was thought at that moment to be a more effective and faster approach to disease treatment. Only two plants were specialized in TCM (Tonghua City Pharmaceutical Factory and Meihekou Number One Pharmaceutical Factory, an offspring of a stateowned TCM wholesale enterprise). These old, formerly family-owned TCM workshops, originally established in the nineteenth century, could be seen as the seedbed for the first generation of TCM plants, providing at least 150 senior pharmacists who developed new drugs, improved age-old preparations, and trained numerous young pharmacists through in-house master-apprentice training systems.

The origins of the first-generation of chemical medicine plants are more complicated. A minority of them originated from chemical medicine-related institutions, such as Western medicine hospitals, of which Baishan Pharmaceutical Plant originating from Tonghua County Hospital is an example. Others were newly-established, but benefited from an external learning and government-controlled assignment of labour.

The R\&D administrative system prior to the mid-1980s was characterized by what LIEBERTHAL (1992) described as "fragmented authoritarianism", in which enterprises and academia across China had no direct link. Tonghua was no exception. The pharmaceutical firms in Tonghua devoted themselves to production. To master production technology, they at the very beginning turned to large-sized pharmaceutical enterprises outside of Tonghua. For example, Ji'an County Pharmaceutical Factory learned how to manufacture oxytetracycline (an antibiotic) from Dalian Pharmaceutical Factory in
Dalian, Shanghai Number Three Pharmaceutical Plant in Shanghai and Wuhan Antibiotics Factory in Wuhan.

In the planned economy period the allocation of labour also differed. Instead of the presentday labour market, in which individuals look for work and enterprises look for staff, school leavers were assigned to lifetime jobs. Personnel mobility was tightly controlled by the government. Government-dominated labour mobility, especially of technical personnel among local firms, did however play an important role in diffusing production technology knowledge in the Tonghua area. More importantly, during the planned economy period, management and technical cadres for Tonghua pharmaceutical industry were selected by the correspondinglevel governments. The promotion and career advancement of these cadres in the hierarchical pyramid of the administrative/party-state system depended on effective operation of the enterprise they managed and on the achievement of production volumes rather than the satisfaction of market demand. Cadre mobility put in place however a relational foundation for closer cooperation between enterprises and government in the subsequent stages of development.

We have to admit that Tonghua pharmaceutical industry is not unique and competitive at this development stage. There were so many TCM areas in China with similar ownership structures, economic size and government-business relations. The early development during this phase however laid the foundations for subsequent long-term industrial development. First, many next-generation TCM firms emerged as a result of the conversion in the late 1980s of some pharmaceutical plants specialized in chemical medicines into TCM enterprises. Second, the first generation enterprises trained a number of skilled employees, and created a specialized labour pool. Last but not least, cadre mobility between government and businesses created a favourable environment for the design of industry-specific policy environments in subsequent stages.

1985-1991 - the takeoff phase: Although the reform and opening-up policy started in 1978, Northeast China, consisting of Heilongjiang, Jilin and Liaoning provinces, did not benefit greatly from these reforms until the mid-1980s. Administrative and fiscal decentralization, that started in the mid-1980s and devolved func- 
tions and expenditure responsibilities to lower level governments, did have a great impact on Tonghua, forcing local governments to find new revenue sources. Many government agencies in Tonghua city acted in ways that resembled corporate local states (OL 1992) or industrial firms (WALDER 1995), and established enterprises to ease fiscal pressure. For example, in Tonghua County alone, Baishan Number Five Plant (transferred to the Dongbao Group) was established in 1984 by the County Light Industry Bureau, the Huinanhuifa Plant and Linhai Plant were established in 1988 by the County Economic and Trade Bureau and the Fangda Plant and Hengan Plant by the Township Enterprises Bureau and the Tonghua City Grain Bureau respectively in 1992. The newly established enterprises were either owned by local government authorities or groups of individuals (legally township-owned), but operated essentially as private enterprises. At the same time, rapid economic growth and increased awareness of health issues together led to a large increase in demand for medicines. The emerging market for nourishing stimulants offered an opportunity for local firms. The resulting local economic development opportunities saw the emergence of a novel organizational form, contracted firms, which subsequently played a decisive role. Contracted firms were a typical form of "organizational hedging or portfolio management, in which actors respond to uncertainty in the organizational environment by diversifying their assets, redefining and recombining resources" (STARK 1996, 997). Although these contracted companies were registered as collective enterprises or legally affiliated to SOE, they were market oriented and enjoyed product development flexibility and were the first to seize the market opportunity to manufacture medicines. Among the pioneer entrepreneurs, Li Yikui was the most outstanding. After graduation from the Peking University, he worked as a technician for ten years in a SOE. Because of a refusal of permission to allow him to commercialize his ginseng royal jelly research results, he left and contracted a loss-making plant (Baishan Number Five Plant) to produce ginseng royal jelly, using the rich ginseng resources of Changbai Mountain. At that time it was however increasingly difficult for small enterprises to secure bank loans because of the transformation of state-owned banks into for-profit organizations. $L i$ Yikui had therefore to rely principally on his extended family network for financial support. His first product, fresh ginseng royal jelly oral liquid, was not new in China, but he changed the product's components, adding for example honey to reduce the herb's bitter taste, and improved the product quality. More importantly, Li Yikui was the first person in China to advertise his products on television. Huge profits from ginseng royal jelly completely changed his financial situation, providing the resources for expansion of the scale of production. Organizational innovation, continuous improvements in quality and marketing innovation made Li Yikui an economically successful businessman. In 1992 the small plant that he had contracted to make medicines was transformed into a legal private economic entity. It subsequently took over several loss-making SOE to emerge today as one of China's pharmaceutical giants.

Fascinated by the success of Li Yikui, the senior managers of SOE and TOE and even government officials started to take over ill-performing enterprises to enter the promising ginsengbased remedies sub-sector of the TCM industry. These companies were basically recentlyestablished town or village enterprises (TVE). At the same time, most of the chemical medicine plants established before the 1980s shifted to the manufacture of ginseng-based products, and the manufacture of chemical medicines ended in Tonghua.

Faced with pressing challenges of fiscal decentralization, in 1987 Tonghua municipal government officially stated that the TCM industry would be developed as a pillar industry. After that date, the local state initiated a series of ambitious economic plans to promote the TCM industry, devoting many human and financial resources to this promising field. In the late $1980 \mathrm{~s}$, as firms inside and outside of Tonghua flooded into this growing field, market competition intensified. Some SOE or newly established TOE fell into an extremely serious financial situation and were privatized in the early $1990 \mathrm{~s}$. At the same time leading enterprises started to diversify their products and to produce TCM drugs to treat diseases. Although the increase in the number of firms in Tonghua itself was small, with just nine start-ups in 1985 to 1991 , output value increased substantially. Improved financial conditions and increasing investment in equipment and especially in automated production lines saw improvements in production technology. 
From a long-term viewpoint, the 1984 to 1991 period was of much importance to the take off of the industry in Tonghua. In that period local pioneer entrepreneurs found new market niches for ginseng-based remedies, and then achieved success by producing at low costs and selling at competitive prices using abundant local TCM resources and mobilizing planned economy assets by for example taking over loss-making enterprises. Quality improvement and market innovation led to higher profits, which together with growing demand lured increasing numbers of enterprises into this sector. The increased number of entrants led to increased competition, which in turn impelled them to develop TCM drugs. In short, the Tonghua industry gradually and successfully opened up a window of local opportunity for the TCM industry initially through the (re)development of ginseng-based remedies by contracted firms. In doing so it acquired some first-mover advantages as a specialized TCM industrial area.

1992-2000 - the transitional phase: The 19922000 period witnessed ups and downs in the number of firms. Firm numbers jumped from 27 at the end of 1991 to 57 in 1992, and then continuously declined in the following four years, reaching 45 in 1996, only to climb subsequently to 64 in 2000 . The reasons for the fluctuation in firm numbers during this stage were related to major changes in national and local institutions. After Deng Xiaoping's southern tour speech in 1992, Chinese society as a whole accepted the existence of private enterprises and created a business-environment that was friendly to them. In that year approximately 30 new, small TCM enterprises were established. However, since the GMP policy was rigorously implemented in China from the early 1990 s, the financial situation of small and middle-sized TCM enterprises worsened, and some of them went to bankrupt.

In the early 1990s the Tonghua area's traditional industries, such as textiles, chemicals, machinery and metallurgy suffered a serious decline in employment and economic output, owing to the shock arising from the rise of the advanced coastal economy. The pharmaceutical industry became increasingly important for the economic and social development of Tonghua city as a whole. In 1995 the Tonghua municipal government launched a historically significant strategy "To construct the pharma- ceutical industry city" (Pharmcity), and encouraged local economic and political elites to take over loss-making enterprises or to establish new TCM enterprises. After that, large numbers of government and enterprise cadres resigned from 'iron rice bowl' jobs to do business (in Chinese: Xiahai). TCM firm numbers in Tonghua increased again after 1996.

Some former government cadres took over unsuccessful enterprises, often at below-market prices. For example, in 1995 Xiu Laigui, a middle-level cadre in Tonghua City Police Department who had strong personal relations with the local drug regulator, took over a small lossmaking SOE and transformed it into a domestic TCM industry champion (Xiuzheng Group). Some other star local enterprises such as Tianma Group, Jinma Group and Wangtong Group all have histories that are similar to that of the Xiuzheng Group in the sense that they were originally SOE and were subsequently taken over by former government officials. In other cases enterprise managers took over the SOE or TVE TCM enterprises that they managed. For example, the Ji'an Plant, the Huinan Plant, and the Baishan Plant were all taken over by their top manager(s) in the late 1990s. In this phase, a few members of the local economic and political elite, mostly of a middle or low-level, created their own private entities from scratch. Many members of the local political elite resigned and served as senior managers of private local TCM enterprises.

During the previous phase quasi-private TCM enterprises re-developed new products based on already existing ones. In the mid-1990s, fake and inferior herbal medicines were widely available in China, and quality improvement was an especially important way of creating and sustaining the competitiveness of individual enterprises (Fig. 1). It was sustained quality improvement that enabled Xiuzheng Group to become domestically competitive. After taking over a small company, Xiu Laigui significantly improved the product quality of a Chinese medicine for treating stomach pains and poor digestion, and then constructed a strong Chinese marketing network. In order to ensure the supply of high-grade raw materials, the Xiuzheng Group also acquired some local raw material enterprises. Moreover, the introduction (in the nineteenth century) of Western medicine to China changed Chinese habits of taking medicines. Traditional TCM dosage 
forms were generally inconvenient to take and hard to absorb. Dosage form development was therefore equally important. However, the transformation of dosage form from a traditional pill, powder or decoction to a modern granule, injection or drip is very complicated. Tonghua TCM enterprises had therefore to construct through personal social networks closer and more frequent relationships with universities and research institutes outside of Tonghua. More interestingly, from the middle of the 1990s the local university (established in 1958) and the vocational school (established in 1980) began to respond actively to the dynamic growth of the Tonghua TCM industry, offering relevant courses, and providing a large number of talented people, although they seldom did research with local enterprises.

This period from 1992 to 2000 was decisive in the development process of this cluster. Many TCM areas declined, even completely leaving the industry, but Tonghua survived. Loss-making TCM enterprises were closed in other areas, in part because this industry was not as economically and socially important to them as it was to Tonghua. Tonghua city made great efforts to sustain this significant local industry, including providing assistance in obtaining loans, and giving priority to the provision of land for production site expansion. Similar efforts were not forthcoming in other TCM areas, enabling Tonghua to establish a very strong foothold in the industry. This smooth transformation of the Tonghua TCM industry was attributable to a large extent to Xiahai cadres.

Although the participation of local elites in business ventures was not totally unique in Tonghua and can be observed in other TCM areas in China, the number of Xiahai cadres in Tonghua was phenomenal: estimates suggest that around 150 former government officials entered the Tonghua TCM industry. This phenomenon had a far-reaching effect on the development of this cluster. First of all, it broke with the traditional Confucian conception of the value orientation of officials (guanbenwei), encouraged people to pursue material wealth, and was helpful in cultivating an entrepreneurial culture. Second, it helped TCM enterprises to upgrade their management capabilities, as former government officials were well-educated and had leadership skills and management abilities. Third, it helped solve difficult problems that enterprises faced, such as access to bank loans and to cheap land for production expansion, through the use of the personal networks of Xiahai cadres. Lastly, it had an impact on the formulation of local development policies that cannot be ignored, as Xiahai cadres often lobbied the current government officials for a favorable environment for TCM development.

2001-2010 - the rapid development phase: The 2001-2010 period was characterized by a steady increase in the number of firms after a short-term decline, the high-speed growth of leading local enterprises through a series of acquisitions, and a movement into formal $R \& D$. In the early 2000 s the number of firms dropped and remained around 55. From 2003 numbers increased steadily, reaching 84 in 2004 and 94 in 2010. The initial decline in the number of firms was largely connected with stricter regulation (GMP policy). In that period, some small and under-performing enterprises were acquired mostly by local pharmaceutical giants. In the subsequent period, spin-off mechanisms and agglomeration economies started to play a significant role, as some technical personnel, managers and salesmen left their employers and founded their own enterprises within the agglomeration. In addition, a number of external entrepreneurs also set up new or acquired bankrupt local firms.

In this period the new startups largely involved green-field investments. Although these new firms contributed to the diffusion of knowledge inside the cluster, their economic performance to date is not very good, in part as the social networks used to mobilize resources were not as strong as those of the local cadres who had established enterprises in an earlier period. As for the external entrepreneurs, they originated mostly from neighbouring TCM clusters, and found it much more difficult to get access to strategic resources (such as land for production expansion) that were already controlled by established local businesses. As a result their overall financial performance was relatively weak, and in the case of bankrupt enterprises did not improve much.

Earlier in 1999 the central government had launched a new national strategy "to make China an innovation-driven nation". A major element of this strategy involved a strengthening of the protection and enforcement of intellectual property rights. At the same time, to tackle 
increasing competition from other pharmaceutical industrial areas, the Tongua municipal government increased investment in physical infrastructures and skills. The strategy of local government in promoting the development of the cluster changed significantly from that of an industrial investor and co-ordinator of the privatization of SOE to that of a facilitator of innovation. Besides lobbying higher-levels of government for preferential policies, the local state played a role as a coordinator of relationships between knowledge-related institutions and TCM-related industries, and in particular with SME, with a hope to make up for the lack of local knowledge. For example, Tonghua local government regularly invited university professors to Tonghua to offer various technology and management courses for SMEs.

At the start of the new millennium, the Chinese government enforced stricter TCM regulation, and the TCM market became increasingly competitive. Together these factors compelled enterprises to attach greater importance to drug safety and effectiveness. Some industrial giants in the Tonghua TCM industry started to develop in-house R\&D laboratories, and also to strengthen R\&D cooperation with knowledge institutions inside and beyond Jilin province. For example, around 2000 the Xiuzheng Group established an in-house technology centre in Changchun High-tech Development Zone, near to a new campus of Jilin University, where the School of Life Sciences is located. This centre was a national scale research centre, involving co-operation with universities inside and outside Jilin Province, and employing over 200 full time scientists. The centre primarily focuses on process innovation, product innovation and dosage form transformation. Another example is the Dongbao Group which with an overseas Chinese scholar jointly created a research-intensive company, Gan \& Lee Pharmaceuticals. Even small TCM enterprises developed their own co-operative R\&D networks with universities.

In addition, some local TCM giants started to undertake large-scale expansion on a national scale by means of acquisitions. To expand rapidly the over-the-counter (OTC) market, the Xiuzheng Group acquired two large-sized state-owned pharmaceutical enterprises (one in Nanchang, and another in Chengdou). To apply biotechnology to TCM, in 2000 or thereabouts the Maoxiang Group acquired a young gene technology research company in Changchun, a spinoff of Changchun Institute of Applied Chemistry, Chinese Academy of Sciences. Similarly, in 2004, the Xiuzheng Group acquired a leading domestic biopharmaceutical company (the Beijing-based Xinluowei Pharmaceuticals). This company is the Xiuzheng Group's main research base.

\section{Conclusions}

We have outlined the evolution of the Tonghua TCM sector, starting in the late nineteenth century, and concentrating on its development through the transition from a planned to a market economy in China in the last thirty or so years. The development of Tonghua as a successful industrial agglomeration owes a great deal to a series of organizational innovations deriving from the change in the wider, national-scale sociopolitical context and changes in institutions and modes of economic governance. Especially important were: (1) the adoption after 1978 of a programme of reform and opening up; (2) the initial development in this context of contract relationships enabling the commercialization of innovations developed in SOE in the planned economy period along with the growth of the market for TCM products; (3) the mechanisms through which some SOE and TOE were transformed into private companies; and (4) the subsequent increase in specialization and competition pushing TCM enterprises to produce TCM drugs as well as invigorants. Alongside these mechanisms however a whole range of local relationships also had significant impacts on the trajectories of different types of TCM enterprise.

EEG provides a set of concepts that permit an interpretation of industrial evolutions, but, in the Chinese context, these models and theories also have some important limitations. These limitations derive in part from the distinctiveness of China's evolving socioeconomic system and environment. Western EEG has concentrated on endogenous local factors, paying insufficient attention to the effects of higherlevel factors. Insufficient attention is also paid to institutional and relational factors operating at various scales, and to theories of the firm and the ways in which the conduct of firms is shaped and in turn shapes their environment.

To deal with these issues an extended multi- 
scalar conceptual framework was developed, identifying the significant roles of four sets of contexts and mechanisms (Fig. 1). The first is the national sociopolitical and economic environment in which local institutions and local economies are embedded. Inside this national configuration, the local institutional context and structures of local interests and power have, secondly, strong impacts on the structure of the industrial system and the relative growth of the diverse groups of enterprises of which it is made up. Emphasis is placed thirdly on the corporate strategies of these heterogeneous enterprises (in terms of resources, technologies and organization) as it is through the actions of firms as shaped by their environment that industrial change occurs. In examining corporate strategies significant emphasis was placed on processes of innovation conceived in a wide sense to embrace technologies, products, research, markets and organization. In the fourth place a set of mechanisms that include relationships with related industries, that result in the selection of enterprises, products and organizational arrangements and that generate changes in industrial structures are identified: e.g. competition, take-overs, spin-offs, labour mobility. Through the interaction of all of these mechanisms the Tonghua cluster of TCM and related industries finally underwent successive reconfigurations and established itself as a leading centre for the manufacture of TCM products in China.

Finally this framework is significant in exploring the application of more general abstract theories and models to the Asian situation. Essentially it recognizes the significance for geography and its concern with spatial differentiation of the social foundations of economic life. These social foundations are associated with different values, different priorities and different rationalities that profoundly shape geographies of development and change.

\section{Note/Acknowledgement}

1 The authors would like to thank Eike W. Schamp (Cologne), Leo van Grunsven (Utrecht) and Christian Berndt (Zurich) and two anonymous referees for valuable comments on earlier drafts of this paper and the interviewees who made this research possible. Any errors are the sole responsibility of the authors. The authors wish to acknowledge the help provided by research funding from several sources: the National Natural Science Foundation of China (41071096),
National Project 973 (2012CB95570002); the UK ES$R C$ grant (RES-062-23-1600) for a project entitled Economic Inter-dependence and Comparative Regional Dynamics in Developed and Developing Economies: Trade and Regional Trajectories in China and the EU; and a Chinese Academy of Sciences Visiting Professorship for Senior International Scientists Grant 2009S1-44.

\section{References}

AmIN, A. (2001): Moving on: Institutionalism in economic geography. In: Environment and Planning A, (33)7, 1237-1242.

Armbruster, H./Bikfalvi, A./Kinkel, S./Lay, G. (2008): Organizational innovation: The challenge of measuring non-technical innovation in large-scale surveys. In: Technovation, (28)10, 644-657.

ArThur, W. B. (1994): Path dependence, self-reinforcement and human learning, In: Arthur, W.B. (Ed.): Increasing returns and path dependence in the economy. Michigan, 133-158.

AsHeIM, B. T./ISAKSEN, A. (2002): Regional innovation systems. The integration of local 'sticky'and global 'ubiquitous' knowledge. In: The Journal of Technology Transfer, (27)1, 77-86.

BATHELT, H./Boggs, J. S. (2003): Toward a reconceptualization of regional development paths: Is Leipzig's media cluster a continuation of or a rupture with the past? In: Economic Geography, (79)2, 265-293.

Boschma, R. A./IAmmarino S. (2009): Related variety, trade linkages and regional growth in Italy. In: Economic Geography, (85)3, 289-311.

Boschma, R. A./Frenken, K. (2006):Why is economic geography not an evolutionary science? Towards an evolutionary economic geography. In: Journal of economic geography, (6)3, 273-302.

Boschma, R. A./Lambooy, J. G. (1999): Evolutionary economics and economic geography. In: Journal of evolutionary economics, (9)4, 411-429.

Boschma, R. A./Martin, R. L. (Eds.)(2010): The handbook of evolutionary economic geography. Cheltenham.

Boschma, R A,./Martin, R. (2007): Constructing an evolutionary economic geography. In: Journal of Economic Geography, (7)5, 537.

Boschma, R. A./Wenting, R. (2007): The spatial evolution of the British automobile industry: Does location matter? In: Industrial and Corporate Change, (16)2, 213-238.

Bramanti, A./Maggioni, M. A. (1997): The dynamics of milieux. The network analysis approach. In: Patti, R./Bramanti, A./Gordon, R. (Eds.): The dynamics of innovative regions. The GREMI Approach. London, 321343.

Cambridge Journal of Regions, Economy and Society (2010): Special issue on The Resilient Region, (3)1.

Chandler, A. D. (1962): Strategy and structure. Chapters in the history of American enterprise. Cambridge. 
Cho, M./Hassink, R. (2009): Limits to locking-out through restructuring. The textile industry in Daegu, South Korea. In: Regional Studies, (43)9, 1183-1198.

Chun, Y. (2012): Restructuring the export-oriented industrialization in the Pearl River Delta, China. Institutional evolution and emerging tension. In: Applied Geography, (32)1, 143-157.

Coe, N. M./Dicken, P./Hess, M. (2008): Global production networks. Realizing the potential. In: Journal of Economic Geography, (8)3, 271.

Coe, N. M./Hess, M./Yeung, H. W./Dicken, P./HenDERSON, J. (2004): 'Globalizing' regional development. A global production networks perspective. In: Transactions of the Institute of British Geographers, (29)3, 468484.

Cooke, P./Gomez Uranga, M./Etxebarria, G. (1997): Regional innovation systems. Institutional and organisational dimensions. In: Research policy, (26)4, 475491.

DAVID, P. A. (1985): Clio and the economics of QWERTY. In: American Economic Review, (75)2, 332-337.

DiCKEN, P. (2007): Global shift. Mapping the changing contours of the world economy. London. (5 $5^{\text {th }} \mathrm{ed}$.).

DUNFORD, M. (2006): Industrial districts, magic circles, and the restructuring of the Italian textiles and clothing chain. In: Economic Geography, (82)1, 27-59.

DUNFORD M/ GRECO L. (2005): After the three Italies. Wealth, inequality and industrial change. Malden.

EisenberG, D. M./Davis, R. B./EtTner, S. L./ApPel, S./Wilkey, S./VAn Rompay, M./Kessler, R. C. (1998): Trends in alternative medicine use in the United States, 1990-1997. In: The Journal of the American Medical Association, (280)11, 1569.

EsSLetzBichleR, J. (2007): Diversity, stability and regional growth in the United States (1975-2002). In: Frenken, K. (Ed.): Applied evolutionary economics and economic geography. Cheltenham, 203-229.

EssletzBichleR, J./Rigby, D. (2005): Technological evolution as creative destruction of process heterogeneity. Evidence from US plant-level data. In: Economic Systems Research, (17)1, 25-45.

EssletzBichleR, J./RigBy, D. L. (2007): Exploring evolutionary economic geographies. In: Journal of Economic Geography, (7)5, 549-571.

Frenken, K./Boschma, R. A. (2007): A theoretical framework for evolutionary economic geography. Industrial dynamics and urban growth as a branching process. In: Journal of Economic Geography, (7)5, 635649.

Frenken, K./VAn Oort, F. G./VerburG, T. (2007): Related variety, unrelated variety and regional economic growth. In: Regional Studies, (41)5, 685-697.

GraBHER, G. (1993): Rediscovering the social in the economics of interfirm relations. In: Grabher, G. (Ed.): The embedded firm. On the socioeconomics of industrial networks. London,1-50.

GrabHer, G./Stark, D. (1997): Organizing diversity. Evolutionary theory, network analysis and postsocial- ism. In: Regional Studies, (31)5, 533-544.

Giulani, E./Pietrobelli, C./Rabellotti, R. (2005): Upgrading in global value chains. Lessons from Latin American clusters. In: World Development , (33)4, 549573.

Hou, ZH.L. (2007): A study about the impetus mechanism of industry cluster in Northeast of China. Changchun. (unpubl. Ph.D. diss., Northeast Normal University, in Chinese).

HuMPhrEY, J. (1995): Industrial reorganization in developing countries. From models to trajectories. In: World Development, (23)1, 149-162.

Humphrey, J./Schmitz, H. (2002): How does insertion in global value chains affect upgrading in industrial clusters? In: Regional Studies, (36)9, 1017-1027.

JiAnG, H./ MurmanN, J. P.(2012): Regional institutions, ownership transformation, and migration of industrial leadership in China. The case of the Chinese synthetic dye industry, 1978-2008. In: Industrial and Corporate Change, 1-38; doi:10.1093/icc/dtr070.

LIEBERTHAL, K. (1992): The 'fragmented authoritarianism' model and its limitations. In: Lieberthal, K./Lampton, D. (Eds.): Bureaucracy, politics, and decision making in post-Mao China. Berkeley, 1-30.

LIU, ZH. G. (2009): The emergence of clusters in societal transition. A coevolutionary perspective on the TCM cluster at Tonghua/China. Frankfurt am Main. (unpubl. $\mathrm{PhD}$ diss.)

Lu, A. P./JiA, H. W./XIAO, C./Lu, Q. P. (2004): Theory of traditional Chinese medicine and therapeutic method of diseases. In: World Journal of Gastroenterology, (10)13, 1854-1856.

MacKinnon, D./Cumbers, A./Pike, A./Birch, K., MCMAster, R. (2009): Evolution in economic geography. Institutions, political economy, and adaptation. In: Economic Geography, (85)2, 129-150.

MARTIN, R. (2000): Institutional approaches in economic geography. In: Sheppard E./ Barnes T.J. (Eds.): A companion to economic geography. Oxford, 77-94.

Martin, R./Sunley, P. (2006): Path dependence and regional economic evolution. In: Journal of Economic Geography, (6)4, 395 -437.

Martin, R./Sunley, P. (2010): The place of path dependence in an evolutionary perspective on the economic landscape. In: Boschma, R./Martin, R. (Eds.): Handbook of evolutionary economic geography. Cheltenham, 62-92.

Metcalfe, J. S. (1998): Evolutionary economics and creative destruction. London.

Nelson, R. R. (1991): Why do firms differ, and how does it matter? In: Strategic Management Journal, (12)2, 61-74.

Nelson, R. R. (1995): Recent evolutionary theorizing about economic change. In: Journal of Economic Literature, (33)1, 48-90.

OI, J. (1992): Fiscal reform and the economic foundation of local state corporatism. In: World Politics, (45)1, 99-126.

Pike, A./Birch, K./Cumbers, A./MacKinnon, D./ MC- 
MASTER, R. (2009): A geographical political economy of evolution in economic geography. In: Economic Geography, (85)2, 175-182.

RAFIQUI, P. S. (2009): Evolving economic landscapes. Why new institutional economics matters for economic geography. In: Journal of Economic Geography, (9)3, 329-353.

SAXENIAN, A. (1994): Regional advantage. Culture and competition in Silicon Valley and Route 128. Cambridge.

Schamp, E. W. (2005): Decline of the district, renewal of firms. An evolutionary approach to footwear production in the Pirmasens area, Germany. In: Environment and Planning A, (37)4, 617-634.

SCHUMPETER, J. (1934): The theory of economic development. Massachusetts.

ScotT, A. (2002): A new map of Hollywood. The production and distribution of American motion pictures. In: Regional Studies, (36)9, 957-975.

Sellar, C./Emilova, M./Petkova Tancheva, C. D./MCNEIL, K. (2011): Cluster policies in Bulgaria. European integration, postsocialist dynamics and local level initiatives. In: International Journal of Urban and Regional Research, (35)2, 358-378.
STARK, D. (1996): Recombinant property in East European capitalism. In: American Journal of Sociology, (101)4, 993-1027.

StORPER, M./WALKER, R. (1989): The capitalist imperative. Oxford

WANG, L.Q. (2006). The research about the forming mechanism and solution of industrial cluters in Tonghua. Changchun. (unpubl. MA thesis, Northeast Normal University, in Chinese).

YeunG, H. W. (2009): Regional development and the competitive dynamics of global production networks. An East Asian perspective. In: Regional Studies, (43)3, 325-351.

YeunG, H.W./Lin, G. (2003): Theorizing economic geographies of Asia. In: Economic Geography, (79)2, $107-$ 128.

ZHou, Y. (2005): The making of an innovative region from a centrally planned economy. Institutional evolution in Zhongguancun Science Park in Beijing. In: Environment and Planning A, (37)6, 1113-1134.

WALDER, A. G. (1995): Local governments as industrial firms. In: American Journal of Sociology, (101)2, 263-301. 